\title{
Environmental efficiency in carbon dioxide emissions in the OECD: A non-parametric approach
}

\author{
O. Zaim* and F. Taskin
}

The role of the environment is an important issue in the policy-making and hence, the accurate assessment of the environmental conditions is vital. In this paper, an environmental efficiency index is developed for the OECD countries using non-parametric techniques. The approach adopted is based on the assumption that there is just one production process behind the production of both goods and pollution emissions. The index derived in this work measures the extent of the required output sacrifice, due to the transformation of the production process, from one where all outputs are strongly disposable to the one which is characterized by weak disposability of pollutants. Using this index, we first conduct cross-section comparisons on the state of each country's production process in its treatment of pollution emissions. We then trace each country's modification of their production processes overtime. The results indicate that if the disposability for $\mathrm{CO}_{2}$ emissions were strictly restricted as the result of an environmental regulation, the total value of output loss to the OECD countries as a whole would correspond to 3.7, 4.8 and 3.5\% of the total OECD GDP for 1980, 1985 and 1990, respectively.

(C) 2000 Academic Press

Keywords: environmental efficiency index, carbon dioxide emissions, non-parametric efficiency measurement.

\section{Introduction}

Growing demands for environmental quality forces policy-makers to consider the environmental impacts of their choices in the formulation of economic policies. As environmental concerns are pronounced increasingly in relation to global commons, environmental issues are treated as international matters. This, not only brings the proposals for a better environmental quality into the international arena but also requires countries to measure, document and publish information about their environmental performance. Hence as an initial step the accurate assessment of environmental conditions is essential.

The objective of this study is two-fold. First, to develop an environmental efficiency index for each of the OECD countries that will show their success in adopting environmentally more desirable technologies. Second, to make an assessment on the required output sacrifice a country should incur in order to become environmentally more efficient. These measures provide information for countries, prior to engaging in international agreements (such as the Luxembourg decision of 1990 which was further reinforced at the Rio Summit of 1992) which aimed at limiting and reducing global emissions.

Early work, involving cross country comparisons of the environmental performance, was based on either descriptive environmental indicators, such as measures of soil salinization, dissolved oxygen in water, and suspended particular matter in air, or performance-based environmental indicators which are measured against some physical threshold or normative policy goal. Examples include measures of compliance with international treaties or target levels of energy use per unit of output. This is the initial approach taken by international institutions such as the World Bank and OECD in their analysis of country comparisons of environmental performances. These measures emphasize only
* Corresponding author Department of Economics, Bilkent University, Bilkent, Ankara, 06533, Turkey

Received 11 March 1998; accepted 10 December 1999 
environmental damage and losses without reconciling economic aspirations with environmental goals. The building blocks of the alternative environmental efficiency index proposed in this study are in accordance with the principles laid down in the Rio Declaration on Environment and Development (1992):

'In order to protect the environment, the precautionary approach shall be widely applied by States according to their capabilities. Where there are threats of serious or irreversible damage, lack of full scientific certainty shall not be used as reason for postponing cost-effective measures to prevent environmental degradation.' (Principle 15)

'National authorities should endeavor to promote internalization of environmental costs and the use of economic instruments, taking into account the approach that polluter should, in principle, bear the cost of pollution, with due regard to the public interest and without distorting international trade and environment.' (Principle 16)

The precautionary approach (Principle 15) calls for the choice of a production plan which is the least detrimental to the environmental quality. That is, among many input, output and pollution emission combinations, it favors the production plan that maximizes the desirable outputs while simultaneously minimizing the resource use and pollution emissions. In addition, the Polluter Pays Principle (PPP) embodied in Principle 16 recognizes that pollutants are not disposable without cost and that some productive resources have to be given up to reduce the levels of pollution emissions. Hence this principle encourages the transformation of the production process from one where outputs (desirable or undesirable) are freely disposable, with no cost to the producer, to the one where disposability of undesirable outputs is limited, by making the disposal of undesirable output costly. The development of the index proposed in this study, starts with the observation that there is one production process behind the generation of desirable outputs and undesirable outputs (pollutants). The approach incorporates efficiency considerations in the production of output, emission of pollutants and resource use (as implied by Principle 15), and measures the opportunity cost of transforming the production process from one where producers do not incur any cost due to emissions of pollutants, to the one where producers incur some losses in terms of foregone desirable output (as implied by Principle 16).

In the context of pollution emissions, environmental efficiency considerations have been taken into account by studies that employ production frontiers techniques. These studies, for which a comprehensive literature survey can be found in Tyteca (1996), mainly concentrated on the analysis of micro level data. For example Fare et al. (1986) examined the impact of environmental regulation on the relative efficiency of US steam electric utilities. Fare et al. (1989b) investigated the magnitude and the sources of relative efficiency changes in the electric utilities before and after regulatory measures are taken. Fare et al. (1989a) investigated the regulatory impact in a sample of 30 US paper mills in 1976. Fare et al. (1996) and Tyteca (1997) developed an environmental performance indicator based on the decomposition of factor productivity into a pollution index, and an input-output efficiency index with an application to data from US fossil fuel-fired electric utilities. This study diverges from the above in its focus on environmental performance at the macro level, and its use of macro data in the construction of (environmental) efficiency indices. The use of macro data in studies that employ production frontier techniques has gained popularity recently (see for example, Fare et al. 1994b; Taskin and Zaim, 1997) but has not been applied in the environmental context.

\section{Model}

In his influential work, Farrell (1957) showed how one can measure productive inefficiency and its components allocative and technical inefficiencies within a theoretically meaningful framework. His initial approach has been adopted and extended by Farell and Fieldhouse (1962), Seitz (1970) Afriat (1972) and Meller (1976). In more recent studies Banker et al. (1984), Fare et al. (1985a), (1994a) showed how one can further decompose Farrell's measure of technical efficiency and extract information on the output loss due to deviations from optimal scale and congestion. This literature, which is referred to 
as 'production frontiers' is extensively covered in the works of Shephard (1970), Fare et al. (1985b), (1994a) and Fried et al. (1993).

Literature on production frontiers is further extended and modified to measure environmental performance in addition to capturing efficiency at the decision-making unit level. The two competing approaches, stochastic frontier estimation and data envelopment analysis, while determining the technology to be used as a basis for constructing different measures of firm performance, share equal responsibility in providing means of measuring environmental performance. As a result, empirical applications on the measurement of environmental performance have flourished from both strands. For example, while Reinhard et al. (1996) used a stochastic production frontier approach to construct environmental efficiency indices at the farm level, Ball et al. (1994) and Tyteca (1997) adopted the data envelopment analysis to measure the environmental performance. Yet Reinhard et al. (1997) used both approaches on the same data set to 'analyze the strengths and weaknesses of the two methods in computing the comprehensive environmental efficiency scores'.

Among the studies which use data envelopment analysis to measure the environmental performance, there are alternative approaches with respect to which type of efficiency measure is chosen. For example, Fare et al. (1996), rely on the comparison of two input (output) oriented radial technical efficiency scores; one that accounts for the production of environmentally undesirable outputs and the other which completely ignores the production of hazardous elements with the desirable outputs. Similarly, Fare et al. (1986) and (1989b) also use radial measures of technical efficiency to compute the desirable output loss which stems from the reduced disposability of the undesirable outputs. In another study, Fare et al. (1989a), as opposed to a radial measure, suggested hyperbolic measure of technical efficiency which allows for simultaneous equiproportionate reduction in the undesirable outputs with an expansion in the desirable outputs. Here, various measures of environmental performance are proposed depending on whether a reduction is sought in inputs together with undesirable outputs.
Studies that focus on the production theory in measuring environmental performance, also differed in their treatment of the sources of undesirable environmental outcomes. Some studies viewed environmental deterioration stemming from the production of 'bads' together with 'goods'. Examples to these are: Pittman, 1983; Fare et al. (1993); Ball et al. (1994) and Tyteca, 1997. Yet, some other studies blamed the environmentally detrimental input usage for continuous deterioration in environmental conditions (for example, Reinhard et al. (1996), 1997; Cropper and Oates, 1992, Boggs, 1997 and Pittman, 1981).

Recognizing that the precautionary approach (Principle 15) implies integration of economic and environmental goals, we adopt the hyperbolic measure of technical efficiency proposed by Fare et al. (1989b). This measure, by seeking the maximum simultaneous equiproportionate expansion for the desirable outputs, and contraction for the inputs and undesirable outputs serves both the economic and environmental goals. The environmental efficiency indices constructed in this study rely on comparing the production processes under alternative assumptions on disposability of 'bad' outputs. In the theory of production, it is assumed that outputs are strongly disposable which implies that the disposal of any output can be achieved without incurring any cost in terms of reduced production of other outputs. However, the symmetric treatment of outputs in terms of their disposability characteristics looses its justification, if one or some of the outputs produced are undesirable goods. Especially in regulated environments, where production units are forced to clean up the undesirable outputs, or to reduce their levels of undesirable output production, one has to treat undesirable and desirable outputs asymmetrically, in terms of their disposability characteristics. Even in the absence of regulations, increased environmental consciousness in the society still requires the treatment of undesirable goods as weakly disposable, i.e. their disposal is achieved by reducing the desirable outputs proportionately.

The recognition that pollutants are not freely disposable, and that some productive resources have to be given up to reduce the levels of undesirable outputs, leads to the outcome of transforming the production process. 
One reason for this transformation is environmental consciousness, which is conceived as the societies' willingness to undertake such institutional reforms that would compel private users of resources and producers of environmental bads, to take account the social cost of their actions (as implied by Principle 16). It is the extent of the required output sacrifice due this transformation which then determines the environmental efficiency and its improvement for society.

Environmental efficiency indices can be constructed by comparing the production processes under alternative assumptions of disposability, using a hyperbolic graph efficiency approach. The underpinnings of the method are shown in Figure 1, which represents the output sets for two piecewise linear technologies with different assumptions on disposability of undesirable outputs.

In Figure $1 U_{g}$ and $U_{b}$ denote desirable output ('good') and undesirable output ('bad'), respectively; if the disposal of bad is costless, the line segment $a b$ would be a feasible part of the technology, since a reduction in $U_{b}$ (a movement from b towards a) would be possible without giving up any $U_{g}$. If, however, the disposal of $U_{b}$ is not costless, then the line segment ab will not be a feasible part of the technology. This is because some resources would be pulled out of the production of $U_{g}$ in order to clean up $U_{b}$, which in turn would imply production of $\mathrm{Oa}$ amount of $U_{g}$ is no longer feasible. Then, it can be said that, the technology bounded by line segments $\mathrm{Oa}, \mathrm{ab}, \mathrm{bc}$ and $\mathrm{cd}$ represents the strongly disposable output technology $P^{S}(x)$, and the

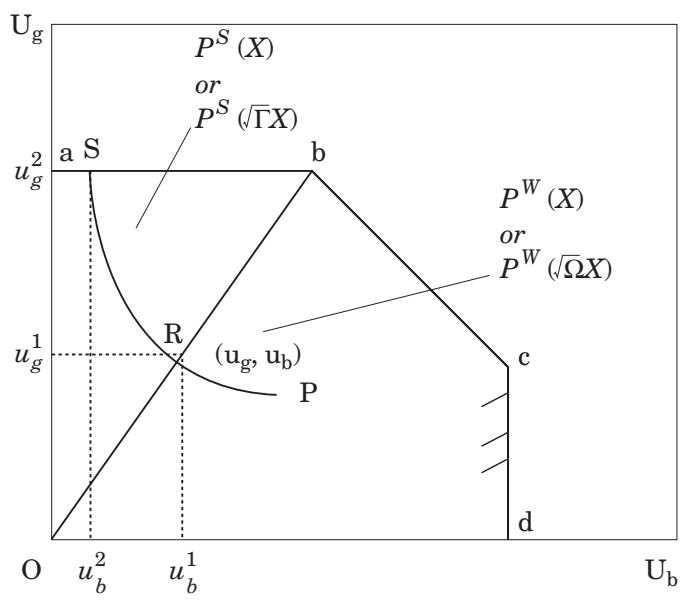

Figure 1. Output sets for strongly and weakly disposable undesirable outputs. technology bounded by line segments $\mathrm{Ob}$, bc and cd represents technology with weakly disposable bads $P_{b}^{W}(x)$. Note here that, we refrain from using the terminology 'weakly disposable output technology' since we still maintain strong disposability assumption on the desirable output. The weakly disposable output technology would be bounded by Ob, bc, co (not drawn on Figure 1).

To describe the theoretical background of the model used, suppose we observe a sample of $K$ production units, each of which uses inputs $x \in R_{+}^{N}$ to produce desirable outputs $y \in R_{+}^{M}$, and undesirable outputs $w \in R_{+}^{J}$. As a matter of notation let $x_{i}^{k}$ be the quantity of input $i$ used by unit $k$ and let $y_{i}^{k}$, and $w_{i}^{k}$ be the quantity of desirable and undesirable output $i$ produced by unit $k$, respectively. These data can be placed into data matrixes $\mathrm{M}$, a $K \times M$ matrix of desirable output levels whose k,ith element is $y_{i}^{k}$, J, a $K \times J$ matrix of undesirable output levels whose $\mathrm{k}$,ith element is $w_{i}^{k}$ and $\mathrm{N}$ a $K \times N$ matrix of input levels whose $\mathrm{k}$,ith element is $x_{i}^{k}$. Using the notation, and assuming that the production process satisfies strong disposability of both outputs (good and bad) and inputs, the Constant Returns to Scale (CRS) output set $P^{S}(x)$ (bounded by $\mathrm{Oa}, \mathrm{ab}, \mathrm{bc}$ and $\mathrm{cd}$ in Figure 1), which denotes the collection of all output vectors $y \in R_{+}^{M}$ and $w \in R_{+}^{J}$ that are obtainable from the input vector $x \in R_{+}^{N}$, can be constructed from observed data by means of:

$P^{S}(x)=\left\{(y, w): z^{T} \mathrm{M} \geq y, z^{T} \mathrm{~J} \geq w, z^{T} \mathrm{~N} \leq x, z \in R_{+}^{K}\right\}$

where $z$ is a $K \times 1$ intensity vector which serves to construct the boundary of the strongly disposable output set from the convex combinations of the observed inputs and outputs. Given two observations $\mathrm{b}$ and $\mathrm{c}$ in Figure 1, the inequalities, $z^{T} \mathbf{M} \geq y$ and $z^{T} \mathrm{~J} \geq w$ allow for feasible vertical extensions to the south, and feasible horizontal extensions to the west respectively, indicating strong disposability for both the desirable and undesirable outputs. Similarly, a CRS technology satisfying the weak disposability of undesirable outputs and strong disposability of desirable outputs and inputs can be represented as an output set as shown below:

$P^{W}(x)=\left\{(y, w): z^{T} \mathrm{M} \geq y, z^{T} \mathrm{~J}=w, z^{T} \mathrm{~N} \leq x, z \in R_{+}^{K}\right\}$ 
where the equality $z^{T} \mathrm{~J}=w$, implies that undesirable outputs in $\mathrm{J}$ are not necessarily strongly disposable, and allows for feasible radial contractions of undesirable outputs to the origin. Intuitively, these equations represent a reference technology from the observed inputs and outputs relative to which technical efficiency of each production unit can be calculated. Equivalently one may chose to define the reference set for a strongly disposable technology and for a weak disposable technology using a graph measure as:

$$
\begin{aligned}
G R^{S}= & \left\{(x, y, w): z^{T} \mathrm{M} \geq y, z^{T} \mathrm{~J} \geq w,\right. \\
& \left.z^{T} \mathrm{~N} \leq x, z \in R_{+}^{K}\right\} \text { and } \\
G R^{W}= & \left\{(x, y, w): z^{T} \mathrm{M} \geq y, z^{T} \mathrm{~J}=w,\right. \\
& \left.z^{T} \mathrm{~N} \leq x, z \in R_{+}^{K}\right\}
\end{aligned}
$$

respectively. The graph of the technology is the collection of all feasible input and output vectors.

The next step in the construction of the environmental efficiency index is the computation of the opportunity cost resulting from the transformation of the production process from one where all outputs are strongly disposable to the one which is characterized by weak disposability of undesirable outputs. Fare et al. (1989a) define this opportunity cost as the ratio of two hyperbolic graph measures of technical efficiencies, calculated from two technologies characterized by two different disposability assumptions. The hyperbolic graph measure of technical efficiency seeks the maximum simultaneous equiproportionate expansion for the desirable outputs, and contraction for the inputs and undesirable outputs.

For a CRS technology which satisfies strong disposability of inputs and outputs (good or bad) hyperbolic graph measure of technical efficiency measure is defined as:

$$
\begin{aligned}
& F^{g}\left(x^{k^{\prime}}, y^{k^{\prime}}, w^{k^{\prime}}\right) \\
& \quad=\min \left\{\lambda:\left(\lambda x^{k^{\prime}}, \lambda^{-1} y^{k^{\prime}}, \lambda w^{k^{\prime}}\right) \in G R\right\}
\end{aligned}
$$

and for each production unit $k^{\prime}$ it can be computed as the solution to the following programming problem:

$$
F_{g}^{S}\left(x^{k^{\prime}}, y^{k^{\prime}}, w^{k^{\prime}}\right)=\min \lambda
$$

subject to LP1:

$$
\begin{aligned}
z^{T} M & \geq \lambda^{-1} y^{k^{\prime}} \\
z^{T} J & \geq \lambda w^{k^{\prime}} \\
z^{T} N & \leq \lambda x^{k^{\prime}} \\
z^{T} & \in R_{+}^{K}
\end{aligned}
$$

or equivalently LP2:

$$
F_{g}^{S}\left(x^{k^{\prime}}, y^{k^{\prime}}, w^{k^{\prime}}\right)=\min \Gamma
$$

subject to:

$$
\begin{aligned}
Z^{T} M & \geq y^{k^{\prime}} \\
Z^{T} J & \geq \Gamma w^{k^{\prime}} \\
Z^{T} N & \leq \Gamma x^{k^{\prime}} \\
Z^{T} & \in R_{+}^{K}
\end{aligned}
$$

For computational purposes these nonlinear programming problems (in LP1) are converted into linear programming problems as in (LP2), where $\Gamma=\lambda^{2}$ and $Z=$ $\lambda z$ and the solution is derived by solving for $\sqrt{\Gamma}$. Note, that for any $\left(x^{k^{\prime}}, y^{k^{\prime}}, w^{k^{\prime}}\right) \in$ $G R, F_{g}^{S}\left(x^{k^{\prime}}, y^{k^{\prime}}, w^{k^{\prime}}\right) \in(0,1]$ measures the maximum equiproportionate deflation of all inputs and undesirable outputs and inflation of all outputs that remain technically feasible.

For a technology that assumes weak disposability for the undesirable outputs, and strong disposability for the desirable outputs and inputs, the following linear programming problem:

$$
F_{g}^{W}\left(x^{k^{\prime}}, y^{k^{\prime}}, w^{k^{\prime}}\right)=\min \Omega
$$

subject to LP3:

$$
\begin{aligned}
Z^{T} M & \geq y^{k^{\prime}} \\
Z^{T} J & =\Omega w^{k^{\prime}} \\
Z^{T} N & \leq \Omega x^{k^{\prime}} \\
Z^{T} & \in R_{+}^{K}
\end{aligned}
$$

can be constructed to obtain a graph measure of technical efficiency for each production unit $k^{\prime}$ as the solution to $\sqrt{\Omega}$. If one translates these measures into a figure, in Figure 1, while computing the hyperbolic graph measure of technical efficiency of a production plan denoted by $\left(u_{g}, u_{b}\right)$ at point $P$ with respect to a technology which assumes strong 
disposability of outputs, point $P$ is compared to point $S$ where the good output is expanded $\left(u_{g}^{2}=u_{g} / \sqrt{\Gamma}\right)$ while simultaneously contracting inputs and the bad output $\left(u_{b}^{2}=\sqrt{\Gamma} u_{b}\right)$ in the relevant output set $\left(P^{S}(\sqrt{\Gamma} x)\right)$. Similarly, the hyperbolic graph measure of technical efficiency of production plan $\left(u_{g}, u_{b}\right)$, with respect to a technology which assumes weak disposability of undesirable good, compares point $P$ to point $R$ where the good output is expanded $\left(u_{g}^{1}=u_{g} / \sqrt{\Omega}\right)$ while simultaneously contracting inputs and the bad output $\left(u_{b}^{1}=\sqrt{\Omega} u_{b}\right)$ in the relevant output set $\left(P^{W}(\sqrt{\Omega} x)\right)$.

Finally the environmental efficiency index can be obtained from the ratio of these two efficiency scores as:

$$
H=\frac{\sqrt{\Gamma}}{\sqrt{\Omega}}
$$

Note that this measure takes a value 1 only for those production units which are on the segments bc and cd or for those production units whose hyperbolic expansions fall on these segments. Since line segments bc and cd are common to both technologies with different assumptions on the disposability of bads, for those production units, it is only natural to expect no opportunity cost for transforming the production process from one where all outputs are strongly disposable to the one which is characterized by weak disposability of undesirable outputs. For production units whose $\mathrm{H}$ index is less than 1, the index indicates that there is an opportunity cost due to aforementioned transformation. The opportunity cost expressed in terms of the percentage of desirable output given up due to the reduced disposability of undesirable output, can be measured as $1-\mathrm{H}$. Therefore $\mathrm{H}$ index can safely be used as a measure of environmental efficiency.

Instead of measuring the loss in desirable output which stems from transforming the technology from one where emission of pollution is free to the one where it is costly, one may want to see the effect of a regulatory standard on pollution emissions on desirable output. The previous approach can also be modified to provide a measure of regulatory impact, conceived in terms of foregone desirable output due to a forced reduction in pollution emissions dictated by quantitative regulatory standards. In this case, the appropriate strategy is to compare two hyperbolic graph measures of technical efficiency scores computed with respect to two technologies both satisfying strong disposability of both inputs and outputs (good or bad), but one containing an additional constraint which incorporates the regulatory standard. For the production unit $k^{\prime}$, the hyperbolic graph measure of technical efficiency with respect to a technology which satisfy the strong disposability of both inputs and outputs (good or bad) and also bounded by the regulatory constraint can be obtained from the solution of the following linear programming problem:

$$
F_{g}^{S}\left(x^{k^{\prime}}, y^{k^{\prime}}, w^{k^{\prime}}\right)=\min \Phi
$$

subject to LP4:

$$
\begin{aligned}
Z^{T} M & \geq y^{k^{\prime}} \\
Z^{T} J & \geq \Phi w^{k^{\prime}} \\
Z^{T} J & \leq w_{*}^{k^{\prime}} \\
Z^{T} N & \leq \Phi x^{k^{\prime}} \\
Z^{T} & \in R_{+}^{k}
\end{aligned}
$$

as $\sqrt{\Phi}$, where $w_{*}^{k^{\prime}}$ denotes the particular quantitative standard for the $k$ th production unit. The percentage of desirable output given up to meet the regulatory standards can now be computed as:

$$
1-\frac{\sqrt{\Gamma}}{\sqrt{\Phi}}
$$

The methods outlined above are applied to construct an environmental efficiency indices for the 25 OECD countries for the period 1980-1990. The results are discussed below.

\section{Data and discussion of results}

While computing the environmental efficiency indices for each of the OECD countries (Table 1), we chose aggregate output as measured by real Gross Domestic Product (GDP), expressed in international prices (in 1985 US dollars) as the desirable output, and $\mathrm{CO}_{2}$ emissions (millions of tons) as the only undesirable output. The two inputs considered are aggregate labor input, measured by the 
Table 1. Hyperbolic efficiency measures with strong disposability of undesirable outputs $\sqrt{\Gamma}$

\begin{tabular}{|c|c|c|c|c|c|c|c|c|c|c|c|}
\hline & 80 & 981 & 982 & 983 & 1984 & 985 & 1986 & 1987 & 1988 & 1989 & 1990 \\
\hline & & & & & & & & & & & \\
\hline & & & & & & & & & & & \\
\hline & & & & & & & & & & & \\
\hline & & & & & & & & & & & \\
\hline & & & & & & & & & & & \\
\hline & & & & & & & & & & & \\
\hline & & & & & & & & & & & \\
\hline & & & & & & & & & & & \\
\hline & & & & & & & & & & & \\
\hline & & & & & & & & & & & \\
\hline & & & & & & & & & & & \\
\hline & & & & & & & & & & & \\
\hline & & & & & & & & & & & \\
\hline & & & & & & & & & & & \\
\hline & & & & & & & & & & & 00 \\
\hline & & & & & & & & & & & \\
\hline & & & & & & & & & & & \\
\hline & & & 0.8 & & & & & & & & \\
\hline & & & & & & & & & & & \\
\hline & & & & & & & & & & & \\
\hline & & & & & & & & & & & \\
\hline & & & & & & & & & & & \\
\hline & & & & & & & & & & & \\
\hline & & & & & & & & & & & 0.9054 \\
\hline New Zealand & 0.8812 & 0.8917 & 0.9106 & 0.9009 & 0.8888 & 0.8779 & 0.8779 & 0.8671 & 0.8439 & 0.8453 & 0.8453 \\
\hline
\end{tabular}

total employment, and total capital stock. The input and the desirable output data are compiled from the Penn World Tables (PWT 5.6) initially derived from the International Comparison Program benchmark studies where cross country and overtime comparisons are possible in real values. Pollution related data were obtained from OECD (1995).

To develop the environmental efficiency index, we used cross-section data on all countries to solve the linear programming problems (LP2) and (LP3) for each country. The solutions determine the efficiency for each country, for a given year, with respect to two OECD multi-output production frontiers constructed under alternative disposability assumptions for the undesirable output. The ratio of the two efficiency scores gives the index of environmental efficiency for a given year. This computation is repeated for each year between 1980 and 1990 to analyze the development of environmental efficiency over time. The efficiency measures and the resulting environmental efficiency index are presented in Table 1, Table 2 and Table 3, respectively. Values in Table 1 and Table 2 show the percentage by which a production unit can contract its resource use and emissions while simultaneously expanding its output and still remain in the respective feasible production sets. For instance the 0.9520 value computed for Canada in year 1980 (see Table 1), shows the factor by which the output can be expanded i.e. $u_{g} / 0.9520$ while simultaneously contracting the pollution emissions i.e. $u_{b} \times 0.9520$ and resource use i.e. $x \times 0.9520$ and still remain in the feasible production set constructed by assuming strong disposability of pollutants. A similar interpretation applies to the values Table 2 , however in this case the contraction (or expansion) factors are measured with respect to a feasible production set constructed by assuming weak disposability for pollutants. The values in Table 3 , are the ratios of corresponding figures in Table 1 and Table 2, and can be used to determine the opportunity cost of transformation (i.e. the impact of reduced disposability of $U_{b}$ ), in terms of potential desirable output loss.

The analysis of the efficiency scores indicates that, for all years in the sample, there are only two countries, USA and Luxembourg, that are fully efficient with respect to both OECD multi output production frontiers constructed under alternative assumptions on the disposability for pollutants. In addition 
Table 2. Hyperbolic efficiency measures with weak disposability of undesirable outputs $\sqrt{\Omega}$

\begin{tabular}{|c|c|c|c|c|c|c|c|c|c|c|c|}
\hline & 30 & 981 & 982 & 1983 & 984 & 985 & 1986 & 1987 & 1988 & 1989 & 990 \\
\hline anada & & & & & & & & & & & \\
\hline & & & & & & & & & & & \\
\hline & & & & & & & & & & & \\
\hline & & & & & & & & & & & \\
\hline & & & & & & & & & & & \\
\hline & & & & & & & & & & & \\
\hline & & & & & & & & & & & \\
\hline & & & & & & & & & & & \\
\hline & & & & & & & & & & & \\
\hline & & & & & & & & & & & \\
\hline & & & & & & & & & & & \\
\hline & & & & & & & & & & & \\
\hline & & & & & & & & & & & \\
\hline & & & & & & & & & & & \\
\hline & & & & & & & & & & & \\
\hline & & & & & & & & & & & \\
\hline & & & & & & & & & & & \\
\hline & & & & & & & & & & & \\
\hline & & & & & & & & & & & \\
\hline & & & & & & & & & & & \\
\hline & & & & & & & & & & & \\
\hline & & & & & & & & & & & \\
\hline & & & & & & & & & & & \\
\hline & & & & & & & & & & & 272 \\
\hline New Zealand & 1.0000 & 1.0000 & 1.0000 & 1.0000 & 1.0000 & 0.9737 & 0.9769 & 0.9624 & 0.9305 & 0.9255 & 0.9119 \\
\hline
\end{tabular}

Table 3. Environmental efficiency measures $H=\sqrt{\Gamma} / \sqrt{\Omega}$

$\begin{array}{llllllllllll}1980 & 1981 & 1982 & 1983 & 1984 & 1985 & 1986 & 1987 & 1988 & 1989 & 1990 & \text { Mean }\end{array}$

$\begin{array}{lllllllllllll}\text { Canada } & 0.9836 & 0.9820 & 0.9885 & 0.9823 & 0.9801 & 0.9783 & 0.9785 & 0.9791 & 0.9804 & 0.9838 & 0.9759 & 0.9811\end{array}$ $\begin{array}{lllllllllllllllll}\text { Mexico } & 0.9063 & 0.9257 & 0.8938 & 0.8794 & 0.9053 & 0.9366 & 0.9382 & 0.9790 & 0.9867 & 0.9914 & 1.0000 & 0.9402\end{array}$ USA $\quad 1.00001 .00001 .00001 .00001 .00001 .00001 .00001 .00001 .00001 .00001 .00001 .0000$

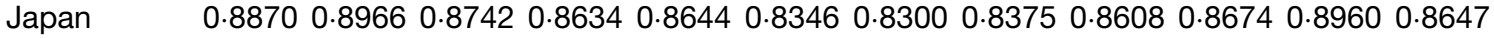
$\begin{array}{lllllllllllll}\text { Austria } & 0.9406 & 0.9222 & 0.9285 & 0.9159 & 0.9006 & 0.9018 & 0.9047 & 0.9037 & 0.9019 & 0.9027 & 0.9144 & 0.9124\end{array}$ $\begin{array}{lllllllllllllll}\text { Belgium } & 0.9746 & 0.9681 & 0.9750 & 0.9608 & 0.9485 & 0.9493 & 0.9512 & 0.9489 & 0.9479 & 0.9477 & 0.9518 & 0.9567\end{array}$ $\begin{array}{lllllllllllllll}\text { Denmark } & 0.9432 & 0.9264 & 0.9438 & 0.9294 & 0.9179 & 0.9356 & 0.9396 & 0.9340 & 0.9292 & 0.9216 & 0.9354 & 0.9324\end{array}$ $\begin{array}{llllllllllllllll}\text { Finland } & 0.9569 & 0.9373 & 0.9498 & 0.9361 & 0.9188 & 0.9379 & 0.9423 & 0.9509 & 0.9381 & 0.9379 & 0.9337 & 0.9400\end{array}$ $\begin{array}{lllllllllllllll}\text { France } & 0.9364 & 0.9236 & 0.9381 & 0.9235 & 0.9028 & 0.9008 & 0.8972 & 0.8955 & 0.8985 & 0.9003 & 0.9079 & 0.9113\end{array}$ $\begin{array}{llllllllllllllll}\text { Germany } & 0.9965 & 0.9959 & 0.9974 & 0.9963 & 0.9939 & 0.9943 & 0.9957 & 0.9929 & 0.9894 & 0.9834 & 0.9709 & 0.9915\end{array}$ $\begin{array}{llllllllllllll}\text { Greece } & 0.9085 & 0.9172 & 0.9097 & 0.9222 & 0.9206 & 0.9442 & 0.9360 & 0.9635 & 0.9699 & 0.9739 & 0.9766 & 0.9402\end{array}$ Iceland $\quad \begin{array}{llllllllllll}1.0000 & 1.0000 & 1.0000 & 1.0000 & 1.0000 & 1.0000 & 1.0000 & 1.0000 & 0.9868 & 0.9648 & 1.0000 & 0.9956\end{array}$ Ireland $\quad \begin{array}{llllllllllll}0.9887 & 0.9858 & 0.9854 & 0.9832 & 0.9787 & 0.9860 & 1.0000 & 1.0000 & 0.9973 & 1.0000 & 1.0000 & 0.9914\end{array}$

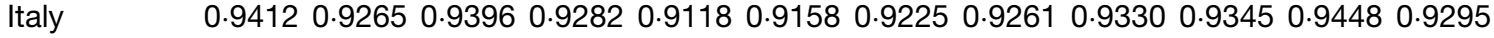
Luxembourg 1.00001 .00001 .00001 .00001 .00001 .00001 .00001 .00001 .00001 .00001 .00001 .0000 $\begin{array}{lllllllllllllll}\text { Netherlands } & 0.9615 & 0.9573 & 0.9556 & 0.9500 & 0.9423 & 0.9474 & 0.9565 & 0.9563 & 0.9597 & 0.9593 & 0.9673 & 0.9557\end{array}$ $\begin{array}{lllllllllllllll}\text { Norway } & 0.9438 & 0.9334 & 0.9412 & 0.9311 & 0.9139 & 0.9225 & 0.9289 & 0.9217 & 0.9130 & 0.9181 & 0.9126 & 0.9255\end{array}$ $\begin{array}{lllllllllllllll}\text { Portugal } & 0.9061 & 0.8892 & 0.8879 & 0.8919 & 0.8809 & 0.9059 & 0.9294 & 0.9461 & 0.9818 & 1.0000 & 1.0000 & 0.9290\end{array}$ $\begin{array}{llllllllllllllll}\text { Spain } & 0.9403 & 0.9481 & 0.9461 & 0.9425 & 0.9186 & 0.9149 & 0.9172 & 0.9259 & 0.9307 & 0.9377 & 0.9347 & 0.9324\end{array}$ $\begin{array}{lllllllllllllllllllll}\text { Sweden } & 0.9269 & 0.9170 & 0.9233 & 0.9059 & 0.8856 & 0.8857 & 0.8896 & 0.8872 & 0.8938 & 0.8766 & 0.8750 & 0.8970\end{array}$ $\begin{array}{lllllllllllll}\text { Switzerland } & 0.9655 & 0.9607 & 0.9706 & 0.9589 & 0.9351 & 0.9400 & 0.9434 & 0.9405 & 0.9367 & 0.9358 & 0.9304 & 0.9471\end{array}$ $\begin{array}{llllllllllllllll}\text { Turkey } & 0.8117 & 0.8045 & 0.8109 & 0.8351 & 0.8557 & 0.9122 & 0.9221 & 0.9714 & 0.9540 & 0.9432 & 0.9736 & 0.8904\end{array}$ $\begin{array}{llllllllllllll}\text { UK } & 0.9963 & 0.9941 & 0.9972 & 0.9980 & 0.9978 & 1.0000 & 1.0000 & 1.0000 & 1.0000 & 1.0000 & 1.0000 & 0.9985\end{array}$ $\begin{array}{lllllllllllllllll}\text { Australia } & 0.9733 & 0.9722 & 0.9855 & 0.9764 & 0.9702 & 0.9701 & 0.9702 & 0.9709 & 0.9667 & 0.9720 & 0.9764 & 0.9731\end{array}$

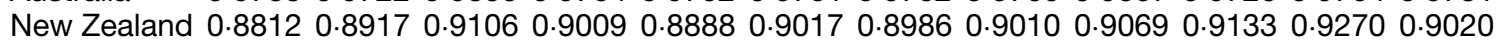




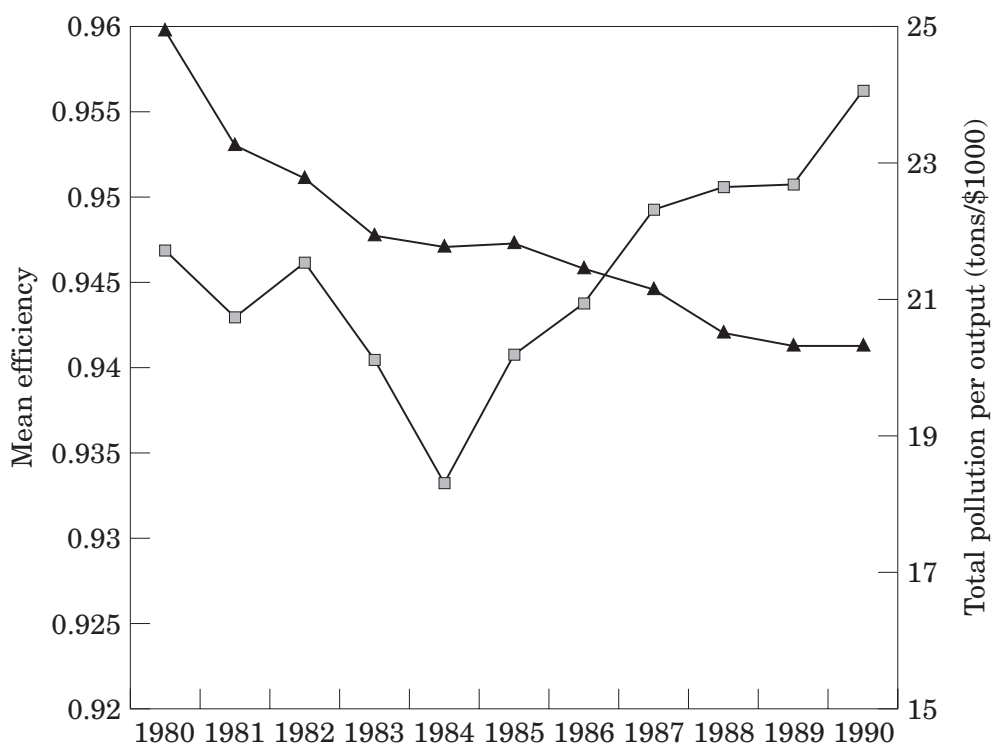

Figure 2. Comparison of mean efficiency and total pollution per output for OECD countries.

to these countries, Italy and Switzerland are always fully efficient with respect to the frontier constructed assuming weak disposability of pollutants but are inefficient with respect to the frontier constructed assuming strong disposability of pollutants. This is as expected theoretically, since the frontier constructed assuming weak disposability of pollutants envelops the data more closely than the frontier constructed using strong disposability assumption for the environmentally undesirable substances. Consequently, the measure of environmental efficiency, defined as the ratio of these two scores, takes the value of one for USA and Luxembourg and less than one for the other two countries mentioned above during the entire sample period.

To elaborate more on the environmental performance of the OECD countries, in Figure 2 we plot the mean value of the environmental efficiency index computed over the 25 countries for the period 1980-1990. The mean index shows the lowest environmental efficiency in terms of $\mathrm{CO}_{2}$ emissions in 1984, and an improved environmental performance since then. We observe that the changes in the efficiency index are also successful in explaining the variation in total pollution per unit output, an alternative indicator which captures the changes in environmental conditions. Figure 2 shows that, from 1985-1988, there is a rapid and simultaneous decline in the total pollution per unit output with improved environmental performance.
Similarly, declining environmental efficiency between the years 1982-1984 dampens the general decline in the total pollution per output.

The analysis reveals that among the 25 countries, USA, Luxembourg, UK, Iceland and Germany are among the best performers and Japan, Turkey, Sweden, New Zealand and France are among the worst, on the basis of mean environmental efficiency computed over the 1980-1990 (see the last column in Table 3). Despite the differences in overall means, countries such as Mexico, Portugal and Turkey showed improved performance while countries like Sweden, Austria and France, exhibited a deterioration.

To investigate the opportunity cost of transforming the production process from one where all outputs (good or bad) are freely disposable to the one where pollution emissions are costly to dispose, we additionally compute the output loss as $(1-H) \times G D P$ in constant 1985 International Dollars. Table 4 shows, for each country, the value of output loss, a country's share in the total OECD output loss, and the output loss per unit of $\mathrm{CO}_{2}$ emission for the selected 3 years. Table 4 suggests that if weak disposability for $\mathrm{CO}_{2}$ emissions were strictly imposed as the result of an environmental regulation, the total value of output loss to the OECD countries as a whole would be 347.8 billion US $\$, 504.2$ billion US $\$$ and 433.3 billion US $\$$ for the years 1980, 1985 and 1990, respectively. These correspond to 


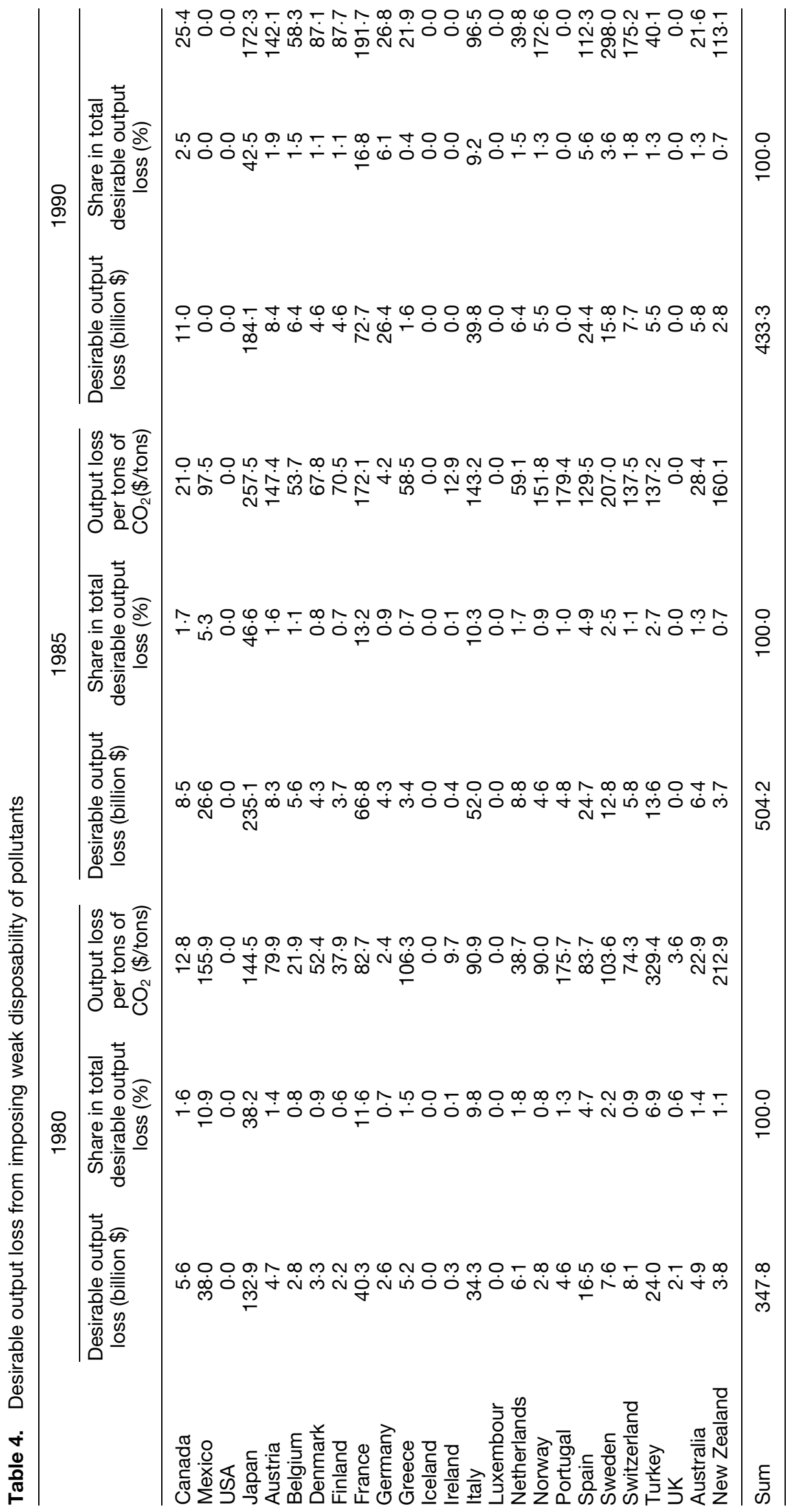


Table 5. Desirable output loss from $\mathrm{CO}_{2}$ reduction schemes

\begin{tabular}{|c|c|c|c|c|}
\hline & $\begin{array}{l}\text { \%1 reduction } \\
\text { (billion \$) }\end{array}$ & $\begin{array}{l}\text { \%3 reduction } \\
\text { (billion \$) }\end{array}$ & $\begin{array}{l}\text { \%5 reduction } \\
\text { (billion \$) }\end{array}$ & $\begin{array}{l}\text { \%10 reduction } \\
\quad \text { (billion \$) }\end{array}$ \\
\hline Canada & 9.4 & $10 \cdot 8$ & IN & IN \\
\hline Mexico & 0.0 & 0.0 & IN & IN \\
\hline USA & IN & IN & IN & IN \\
\hline Japan & 131.5 & 134.5 & 137.5 & 144.8 \\
\hline Austria & 7.4 & 7.6 & 7.7 & 8.1 \\
\hline Belgium & 5.7 & $6 \cdot 0$ & $6 \cdot 3$ & IN \\
\hline Denmark & 3.2 & 3.3 & 3.5 & 3.9 \\
\hline Finland & 3.5 & $3 \cdot 6$ & 3.8 & 4.2 \\
\hline France & IN & IN & IN & IN \\
\hline Germany & $13 \cdot 0$ & 14.7 & $16 \cdot 3$ & 20.5 \\
\hline Greece & 0.0 & 0.0 & 0.0 & 0.0 \\
\hline Iceland & 0.0 & 0.0 & 0.0 & IN \\
\hline Ireland & IN & IN & IN & IN \\
\hline Italy & IN & IN & IN & IN \\
\hline Luxembourg & IN & IN & IN & IN \\
\hline Netherlands & $5 \cdot 6$ & $6 \cdot 0$ & IN & IN \\
\hline Norway & $5 \cdot 3$ & 5.4 & 5.4 & IN \\
\hline Portugal & IN & IN & IN & IN \\
\hline Spain & $21 \cdot 7$ & 23.7 & IN & IN \\
\hline Sweden & IN & IN & IN & IN \\
\hline Switzerland & IN & IN & IN & IN \\
\hline Turkey & 0.0 & 0.0 & 0.0 & 0.0 \\
\hline UK & IN & IN & IN & IN \\
\hline Australia & 0.8 & 1.3 & 1.7 & 4.0 \\
\hline New Zealand & $2 \cdot 2$ & $2 \cdot 3$ & $2 \cdot 4$ & $2 \cdot 6$ \\
\hline
\end{tabular}

IN: infeasible.

3.74 .8 and $3.5 \%$ of the total OECD GDP for these 3 selected years, respectively. In terms of the impact of such a regulation on individual countries, in USA, Luxembourg and Iceland, environmental regulation is not binding so that there is no loss in output. However, in terms of foregone output as a percentage of the total OECD loss, Japan (38.2\%), France (11.6\%) and Mexico (10.9\%) in 1980; and Japan (42.5\%), France (16.8\%) and Italy $(9.2 \%)$ in 1990 are the countries that would assume the largest share due to this transformation. These results are quite robust with regards to the choice of technique in evaluating the cost of pollution reduction. In fact, an OECD report (OECD, 1991) which simulates the cost of reducing $\mathrm{CO}_{2}$ emissions within a general equilibrium modelling framework also ranks France and Japan among the countries which will incur the highest costs.

An alternative interpretation emerges when the output sacrifice can be considered as the required level of penalty that should be imposed on each country to force them to transform their technologies. These amounts, computed for each ton of $\mathrm{CO}_{2}$ emissions, are reported in the third columns of the corresponding year in Table 4. When countries are ranked in terms of the magnitude of the required output sacrifice per ton of $\mathrm{CO}_{2}$ emitted, a different ordering emerges. In this regard we observe Turkey, Portugal and Mexico in 1980, Japan, Sweden and Portugal in 1985 and Sweden, France and Switzerland in 1990 as countries incurring the highest burden per ton of $\mathrm{CO}_{2}$.

In a final analysis, we evaluate the impact of a regulatory standard on pollution emissions. One such standard is to dictate an across the board proportional reduction in $\mathrm{CO}_{2}$ emissions. ${ }^{1}$ Table 5 reports the impact of four alternative reduction schemes on the required desirable output for each country in 1990. Some important conclusions emerge from the comparisons of the output loss due to the proportionate reduction of the $\mathrm{CO}_{2}$ emissions and the output loss from imposing weak disposability of undesirable outputs. For all countries, the output loss due to the

\footnotetext{
${ }^{1}$ For example, in simulating the effects of across the board proportional reductions of the $\mathrm{CO}_{2}$ emissions on the desirable output, in linear programming problem LP4, we choose $w^{k}$ to be $0.99 \times w^{k}$ for $1 \%$ reduction in the total $\mathrm{CO}_{2}$ emission.
} 
imposed regulation (for all alternative levels of $\mathrm{CO}_{2}$ reductions) is always less than the output loss associated with weak disposability of pollutants. This is as expected theoretically because the weak disposability of pollutants assumption is the most restrictive constraint when compared with other restrictions. Consequently, for those observations that are fully efficient with respect to the weakly disposable output set, even the slightest reduction in $\mathrm{CO}_{2}$ emissions will not be possible, implying infeasible solutions. From the cross analysis of Table 5 and Table 2, one can see that USA, France, Ireland, Italy, Luxembourg, Portugal, Sweden, Switzerland and UK are examples of such cases where a reduction in $\mathrm{CO}_{2}$ emissions is infeasible. For countries which are not efficient with respect to the weakly disposable output set, whenever the output loss that results from a certain percentage of $\mathrm{CO}_{2}$ reduction exceeds the output loss implied by the weak disposability, the imposition of the regulation leads to an infeasible outcome. On the other hand, for another group of countries the regulatory standard is not binding, implying that they can reduce their $\mathrm{CO}_{2}$ emissions without incurring any desirable output loss. For the cases presented in Table 5, Turkey and Greece, for all the alternative proportionate $\mathrm{CO}_{2}$ reductions, Iceland, up to $10 \%$ reduction and Mexico up to 5\% reduction, are examples of cases where constraints are not binding. Overall this analysis shows that, while an across the board $1 \%$ reduction in $\mathrm{CO}_{2}$ emissions is feasible for 16 countries, a $10 \%$ reduction in $\mathrm{CO}_{2}$ emissions is feasible for only nine out of 25 OECD countries.

\section{Conclusion}

Using production frontier methodology, this paper develops an environmental efficiency index for the OECD countries, which allows temporal and cross country comparisons for the period 1980-1990. In contrast to methods which gauge the environmental efficiency with the levels of emissions of pollutants, the index developed in this study is based on a production approach that explicitly differentiates between the disposability characteristics of the environmentally desirable and undesirable outputs. Employing this measure, the value of desirable output loss associated with weak disposability of pollutants for each country and their share in the total OECD output loss are computed. The results indicate that, while transforming their production processes in order to take environmental considerations into account, Japan and France are two countries that would carry the largest burden. Furthermore, the impact of across the board proportionate reductions of $\mathrm{CO}_{2}$ emission on the desirable output of each country is evaluated for 1990 and the results reveal that a $10 \%$ reduction in $\mathrm{CO}_{2}$ emissions is feasible for only nine out of 25 OECD countries while $1 \%$ reduction is feasible for 16 countries.

\section{References}

Afriat, S. N. (1972). Efficiency estimation of production function. International Economic Review 13, 568-598.

Ball, V. E., Lovell, C. A. K., Nehring, R. F. and Somwaru, A. et al. (1994). Incorporating undesirable outputs into models of production: an application to the US agriculture. Cahiers d'Economie et Sociologie Rurales 31, 60-74.

Banker, R. D., Charnes, A. and Cooper, W. (1984). Models for estimation of technical and scale inefficiencies in data envelopment analysis. Management Science 30, 1078-1092.

Boggs, R. L. (1997). Hazardous Waste Treatment Facilities: Modelling Production with Pollution as Both an Input and an Output. PhD Thesis. University of North Carolina, Chapel Hill, North Carolina.

Cropper, M. L. and Oates, W. E. (1992). Environmental economics: a survey. Journal of Economic Literature 30, 675-740.

Fare, R., Grabowski, R. and Grosskopf, S. (1985a). Technical efficiency in Philippine agriculture. Applied Economics 17, 205-214.

Fare, R., Grosskopf, S. and Lovell, C. A. K. (1985b). The Measurement of Efficiency of Production. Boston, Kluwer-Nijhoff.

Fare, R., Grosskopf, S., Lovell, C. A. K. and Pasurka, C. (1989a). Multilateral productivity comparisons when some outputs are undesirable. The Review of Economics and Statistics 71, 90-98.

Fare, R., Grosskopf, S. and Pasurka, C. (1989b). The effect of environmental regulations on the efficiency of electric utilities: 1969 versus 1975. Applied Economics 21, 225-235.

Fare, R., Grosskopf, S., Lovell, C. A. K. and Yaisawarng, S. (1993). Derivation of shadow prices for undesirable outputs: a distance function approach. Review of Economics and Statistics 75, 374-380. 
Fare, R., Grosskopf, S. and Lovell, C. A. K. (1994a). Production Frontiers, Cambridge: Cambridge University Press.

Fare, R., Grosskopf, S., Norris, M. and Zhang, Z. (1994b). Productivity growth, technical progress and efficiency change in industrialized countries. The American Economic Review 84, 66-83.

Fare, R., Grosskopf, S. and Pasurka, C. (1986). Effects on relative efficiency in electric power generation due to environmental controls. Resources and Energy 8, 167-184.

Fare, R., Grosskopf, S. and Tyteca, D. (1996). An activity analysis model of the environmental performance of firm: application to fossil fuel electric utilities. Ecological Economics 18, 161-175.

Farrell, M. J. (1957). The measurement of productive efficiency. Journal of the Royal Statistical Society, series A 120, 253-281.

Farell, M. J. and Fieldhouse, N. (1962). Estimating efficient production function under nonincreasing returns to scale. Journal of Royal Statistics Society, series A 125, 252-267.

Fried, H. O., Lovell, C. A. K. and Schmidt, S. S. (eds) (1993). The Measurement of Productive Efficiency: Techniques and Applications. Oxford: Oxford University Press.

Meller, P. (1976). Efficiency frontiers for industrial establishments of different sizes. Explorations in Economic Research 3, 379-407.

OECD (1991). The Costs of Policies to Reduce Global Emissions of $\mathrm{CO}_{2}$ : Initial simulations with GREEN. OECD Department of Economics and Statistics. Working papers. No. 103, Paris.

OECD (1995). Environmental Data Compendium. 288 pp. OECD, Paris.
Pittman, R. W. (1981). Issues in pollution control: interplant cost differences and economies of scale. Land Economics 57, 1-17.

Pittman, R. W. (1983). Multilateral productivity comparisons with undesirable outputs. Economic Journal 93, 883-891.

Reinhard, S., Lovell, C. A. K. and Thijsen, G. J. (1996). Econometric Estimation of Technical and Environmental Efficiency: An Application to Dutch Dairy Farms. Paper Presented at the Georgia Productivity Workshop II, Athens, GA, November 1996.

Reinhard, S., Lovell, C. A. K. and Thijsen, G. J. (1997). Environmental Efficiency with Multiple Environmentally Detrimental Variables; estimated with SFA and DEA. Wageningen Economics Papers, WEP issue, 07-97.

Seitz, W. D. (1970). The measurement of efficiency relative to a frontier production function. American Journal of Agricultural Economics, 52, 505-511.

Shephard, R. W. (1970). Theory of Cost and Production Functions. Princeton, NJ: Princeton University Press.

Taskin, F. and Zaim, O. (1997). Catching-up and innovation in high- and low-income countries. Economic Letters 54, 93-100.

Tyteca, D. (1996). On the measurement of environmental performance of firms: a literature review and a productive efficiency perspective. Journal of Environmental Management 46, 281-308.

Tyteca, D. (1997). Linear programming models for the measurement of environmental performance of firms-concepts and empirical results. Journal of Productivity Analysis 8, 183-198. 